\title{
Labyrinthe
}

$11 \mid 2002$

Numéro 11

\section{Icônes et iconoclasmes dans la littérature, les arts et les sociétés d'Amérique du Nord}

\section{Françoise Coste}

\section{(2) OpenEdition \\ 1 Journals}

\section{Electronic version}

URL: http://journals.openedition.org/labyrinthe/672

DOI: $10.4000 /$ labyrinthe. 672

ISSN: 1950-6031

\section{Publisher}

Hermann

\section{Printed version}

Date of publication: 14 January 2002

Number of pages: 139-145

\section{Electronic reference}

Françoise Coste, «Icônes et iconoclasmes dans la littérature, les arts et les sociétés d'Amérique du Nord », Labyrinthe [Online], 11 | 2002, Online since 15 April 2005, connection on 21 April 2019. URL: http://journals.openedition.org/labyrinthe/672 ; DOI : 10.4000/labyrinthe.672

This text was automatically generated on 21 April 2019.

Propriété intellectuelle 
Icônes et iconoclasmes dans la littérature, les arts et les sociétés d'Amérique du Nord

Françoise Coste 